\title{
Exploring How Silence Communicates
}

\author{
Dat Bao \\ Monash University, Australia \\ dat.bao@monash.edu
}

\begin{abstract}
This article argues that silence as communication can be academically practised in the classroom as much as talk, simply because talk and silence are both essential components of everyday interaction (Nakane, 2012). These two constructs are interdependent in the sense that one would not exist without the other. Silence can be practised in two different ways: one is to employ it as a mental processing process in learning; two is to observe and discuss how silence is used in communication. The article begins by sharing the literature review on how silence works in education, how it deserves a place in SLS theorisation, and how it constitutes communication competence. Secondly, it highlights classroom tasks that trigger silent processing and explain why this is the case. Thirdly, the discussion recommends an activity which addresses the value of silence, which was developed by the author through research and experience. Finally, there are recommendations for task design in which similar activity types are introduced to assist the learning of reflective students.
\end{abstract}

Keywords: silence, talk, mental processing, inner speech, private speech

How to Cite: Bao, D. (2020). Exploring how silence communicates. English Language Teaching Educational Journal, 3(1), 1-13.

\section{INTRODUCTION}

The duality of speech and silence in communication deserve more attention in academic discourse. Language teaching is not always about talk. In the real world, effective communication is both about speech and silence. Sometimes, we express ourselves through words but at other times, we speak better without them. For example, when a friend is internalising from the loss of a loved relative at a funeral, quiet sympathy would be essential unless one finds helpful words to say and locates the right moment. Because of this duality in the nature interaction, it is absurd to only rely on what we hear to make sense of the world, but there is the need to rely on feeling, observation, understanding, knowledge, empathy, and other non-verbal clues such as eye contacts, gestures, movement, tone, posture, and artefacts. In a word, while speaking out fluently is an essential ability; employing silence productively represents another major capability as well (Bao, 2014).

\section{The discourse on how silence works}

The silence and talk can be equal in communication values. If we ask two people: 'Do you agree?' One person may say 'no'; while the other person may simply keep silent. Both responses seem to denote the same attitude, that they do not agree. As Zembylas \& Michaelides (2004: 207) explain, 'silence can be colonized by talk, of course, but meaning cannot. suggests that while talk might dominate as an utterance system, silence can operate as a productive system of its own. In many cases, it is the structure of silence among talk intervals that help enhance articulation quality. Because of this, in reviewing silence, it would be unreasonable to remove talk from the background of the discussion, simply because without the presence of talk, one cannot recognise how silence really occurs. This project investigates students' ways of responding to classroom tasks and documents their justification when a decision on participating modes is made. Based on this, 
recommendations are offered to task design. Being able to comprehend the rationale behind decisions to cope with a task will benefit tasks in optimising students' learning strengths.

To understand classroom silence is one step forward in uncovering the learning mechanism. As educators, we need to 'hear' and interpret silence attentively, not only from experience but also on the foundation of research, without which we might, in the words of Zembylas \& Michaelides (2004: 207), happen to conduct 'teaching with ignorance'. Although the current discourse has expressed appreciation for the silent mode of learning (see, for example, Creelman, 2017) and has recognised students' choices to be either silent or verbal, not much research has unpacked the process of students' verbal or non-verbal behaviour as tactically influenced by task characteristics. This article responds to this gap through an empirical project that sheds light on the relationship between the nature of the task and students' responses in either spoken or reflective ways.

\section{In search of silence in SLA theories}

Silence is an under-explored theme in the mainstream literature on second language acquisition and on the methodology of teaching a second language (Bao, 2019). Silence is a hard topic to deal with when it comes to empirical research, simply because when learners talk, the research can record data for analysis, yet when learners are speechless, data hardly exist for one to collect and read. In fact, the association between words and silence have historically divided Eastern and Western social, educational, and academic attitudes over the past century toward which one is the more cherished mode of communication (Zembylas, 2008; Belanoff, 2001). While in some non-Western cultures, silence may be required to express a role or a voice, in many Western contexts, the obsession with words sometimes causes one to be intolerant toward silence and view the wordless person as subordinate, or in Karmen's (2001, p. 4) words, as being 'inadequately educated'.

Believe it or not, more research on silence has come from other disciplines including psychology and sociology than research in second language acquisition. Although the discourse has embraced rich discussion on the silent period (Krashen, 1985), the innerspeech stage (Vygotsky, 1986), internalisation (Winegar, 1997), private speech (SavilleTroike, 1988), and inner voice (Tomlinson, 2001), it has been acknowledged that today's research on inner speech is not much easier than such research in Vygotsky's time (Ehrich, 2006). Given all the subtleties and complexities of human talk that makes it hard to research on talk (Edwards \& Westgate, 1987), research on silence is many times more difficult as there is virtually no scientific method to transcribe silence.

As a constantly evolving discipline in the fields of linguistics and psycholinguistics, second language acquisition was initially concerned with cognition and over the years has moved to exploring affect (Chambers, 2007) as well as other areas in language development. Despite such dynamics, the role of silence in L2 education has been treated with great caution and, as far as research findings are concerned, has hardly been connected to learning abilities in optimistic ways. Scholarly research during the 1960s and 1970s pointed out that children who remain reticent in class were often perceived as socially and intellectually incompetent (Gordon \& Thomas, 1967) as they make poorer school progress than their peers (Feshback et al., 1974; Stevenson et al., 1976; Colligan, 1979). In fact, silence in SLA discourse until the 1980s was mentioned as resistance to speech (Harder, 1980), difficulty in performance, and lack of comprehension (Dulay et al., 1982; Gibbons, 1985). While acknowledging silence as the initial stage of language study, SLA scholarly research until recently remains uncertain about how to proceed to address the continuing 
role of silence in the 'post-silent era' - a term which indicates the end of silent film era and which is mentioned to criticise how excessive talk can weaken the subtlety of communicative silence. Although this debate in the movie industry seems irrelevant to language learning, it reminds us that silence should be seen more than just a period when we were hopeless due to the inability to produce speech and that silence continues to play a significant role in L2 development. In fact, SLA shows less interest in private speech than overt production (Saville-Troike, 1988) and seems 'insufficiently curious about silence as part of the second language learning process' (Granger, 2004, p. 30).

\section{Silence as communicative competence}

It is important to note that silence, historically, has an integral role in communicative competence ever since the 1960s. According to Hymes (1967; 1972), language competence comprises three elements: knowledge, ability and actual use. Although silence may allow space for the construction of knowledge and ability, it may not show evidence of the actual use of language. The gap between silence and actual verbal communication, however, is not always clear-cut due to the existence of private speech and internalisation. Private speech can happen in silence, through whispering to oneself or others, or in spoken and written form. It serves to draw one's own attention (Frawley, 1997) and has a self-regulatory nature (John-Steiner, 1992). All of these skills are able to function thanks to learners' exposure to social interaction and therefore it is hard to say that silence is far removed from verbal communication. Instead, the internal world and the social world can be quietly negotiated in learners' mental processes. Such negotiation, which is known as internalisation (Winegar, 1997), has the potential to become useful in future communication.

Although it is commonly acknowledged that silence plays a role in monitoring language, it remains a mystery how exactly that role can help develop communication strategies. Strategic competence is the ability to make conversational plans and compensate for difficulties in verbal communication (Canale \& Swan, 1980). Even though one can quietly internalise such strategies through attentive listening, observing others' communication, and engaging in self-directed speech, the development of such competence needs to be negotiated within the framework of language use (Bachman \& Palmer, 1996). So far, the relationship between silent observation and strategy development has rarely been a concern in second language acquisition research.

Oxford (2001) argues that there is a connection between learning and social skills: those who are good at social communication strategies often tend to be good at language learning strategies. Based on this understanding, if silent learners develop effective ways to learn L2, they have potential to develop social skills. These abilities, which Celce-Murcia et al. (1995) refer to as interactional competence, requires practical actions such as managing social introduction, turn-taking, initiation of talk, closing conversation, changing topics, interrupting, recognising the difference between L1 and L2 social norms, and so on. Someone who remains silent from such practice may experience difficulty in communication.

One may need to keep in mind that silence, in a similar vein to talk, is not contextfree. If talk has to be socioculturally appropriate depending on who, where, when, what role and what content, silence as part of language also shares similar needs in order for one to be welcome, accepted, valued and understood rather than to cause confusion and misinterpretation. Celce-Murcia et al. (1995) maintain that social competence includes factors such as power, politeness, and cultural awareness. Arguably, if these elements play a role in how one communicates through talk, they also must play a role in how one appropriately keeps silent. In other words, to keep silent cannot be a decision made by the silent language user alone but is contingent upon social situations. In the context of the 
classroom where the regulation to moderate between silence and talk is negotiated and codecided by both the teachers and students, silence needs to take place within the expectation of the class society rather than occur accidentally.

On an additional note, today's changing globalised contexts may prompt the need to research on silence beyond a face-to-face learning mode, that is, online silence. Nowadays as words such as 'interaction' and 'chat' are placed on Google search, their meanings often take on a digital connotation. Likewise, the concept silence has altered its meaning as the nature of communication in the digital age constantly changes. As much as the concepts of social presence and social interaction have been modified (Gunawardena et al., 2001; Leh, 2001), silence can also refer to the state of being quiet from writing rather than from talking (Zembylas \& Vrasidas, 2007). When someone is not making written comments during engagement with online discussion, the person is considered as keeping quiet. Silence in this sense indicates social and psychological distance between humans, that is, the lack of attentiveness, engagement, responsiveness, and participation. The need to understand the nature of and reasons for such types of silence should be studied alongside the need to improve online learning and communication.

\section{RESEARCH METHOD}

This article itself is not a research study, but it follows up on two empirical projects conducted by the authors. The former took place during 2009 - 2013 (Bao, 2014) and the latter happened during 2018 - 2019 (Bao, 2014). Both of the studies have been systematically reported in academic publications. The first project was a qualitative, phenomenological study in which Bao (2014) interviewed 100 participants for two years to find out how these learners developed their language proficiency through silence. It was followed up with the author's connection of the study outcome with the current debate in SLA discourse (Bao, 2019). The second project is also a qualitative, phenomenological study in which 10 East-Asian participants were interviewed about how they responded to classroom tasks through the use of both silence and talk, with analysis related to when silence and talk occur respectively.

The article, which is a follow-up on the above projects, responds to the appeal for knowledge about silence to be pushed further and becomes classroom pedagogy. The article focuses on a new activity, whose type is extremely rare in English language education. The activity, again, is founded upon the author's two previous research studies, as mentioned above, about the use and value of the silent learning style in second language acquisition. In particular, two important research findings lay the foundation for the activity propose in this article. One is the need for silence to enter into task design; and two is the need to understand task types which allow for silent processing of information. These needs, which come from research effort, are explained in the subsequent section.

\section{FINDINGS AND DISCUSSION}

The first finding, which comes from the project conducted by Bao (2014), concluded that silence needs to be incorporated in classroom tasks. Without this awareness and practice, communication would be unreal. Teachers would continue to pretend that talk makes up $100 \%$ of everyone's communicative repertoire. Bao $(2014 ; 2019)$ has discovered that in many teachers' practical experiences, not every individual student who is highly articulate would demonstrate better academic skills than those who speak sparingly. For this reason, relying solely on students' verbal participation to judge their ability and learning 
enthusiasm would seem to be an inadequate approach to educational practice. Even when we become aware of this reality, to be able to comprehend how students learn effectively in silence remains a challenging task.

The second finding, which arrives from an empirical study by Bao (2020), highlights that a number of classroom tasks actually trigger silent learning and intense mental processing, a reality that many teachers are unaware of. Collecting narrative data from 10 East-Asian students in Australia, Bao was discovered that there are certain types of classrooms that actually require more silent processing than spontaneous talk; and if the teacher unknowing stress students out to come up with immediate responses, that pedagogy would ruin the discussion, risking low understanding of the learning process and risking poor quality contribution from students. Such tasks would offer personal space and wait time, not requiring peer interaction, challenging the mind, inviting personal reflection, asking for a written response, and organising cognitive processing of rules or methods. They encourage students to work alone and produce output such as a written summary, an idea, an account of experience, and solutions to problems.

Of course, there are tasks that would that elicit verbalisation right away. They include, for example, fluency tasks (which involve spontaneous responses for verbal skills development), exploratory tasks (which involve peer discussion), communication and feedback tasks (which involve mutual support), collaborative projects (such as producing a poster, a video clip, or a summary), post-tasks (which follow up a main task for sharing further thoughts), and game-like tasks (which encourage teamwork, competition, and enjoyment). The common characteristic of these activities is that they involve collaborating with classmates rather than functioning alone, with clear emphasis on fluency, rehearsal, communication, collaboration, and sharing. They prompt talk by requiring quick, spontaneous answers or reactions, which focus on the process rather than outcome and are often not of a cognitively demanding type. Arguably, tasks that go well with their knowledge and experience will give them the confidence to speak out more; and tasks of an informal nature that require no right or wrong answer also make students feel relaxed enough to participate.

\section{The proposed activity}

This section, which is the main part of the article, proposes a classroom activity in which silence is used as a discussion topic. In addition, silence is also employed as part of the learning process whereby learners watch a video clip from a movie, reflect on the content, take notes, and later on join a verbal discussion if they wish. Observing and listening to silence attentively is an important skill in communication. This is an activity which the author designed and implemented for the first time in 2020 at Monash University. The task has four steps: experience sharing, observation, reflection and discussion, as will be elaborated below.

\section{Sharing your experience}

Think about moments of tension or conflict in your life. When was the last time you experience such a moment? Where? In what situation? With who? How long did tension last? How was it resolved?

Ex. You are waiting for someone or some news anxiously, not knowing when or even if at all that person/news will arrive.

Ex. You are struggling to express yourself in a specific situation and not sure if you should speak out or keep quiet. You want a promotion; someone bullies you, etc.

Share that with the person next to you. 
In that experience, which tool seemed work for you: talk to explain, or silence to let things work.

Observe a movie scene

Watch this movie scene, as in the link below, to see an interesting example of the above. Please also refer to the Appendix at the end of this article to form an idea of what the conversation in the movie scene is about.

https://www.youtube.com/watch?v=_Hvc1Ae-YCU

You will notice that the first half of this scene is filled with words: you need to listen. The second half take place almost without words: you need to observe.

Discussion questions

1. Which detail in this scene is your favourite moment?

2. In the end, why didn't Akatsuka kill Ichi with his sword when Ichi had no weapon?

3. Suppose you are to add more dialogues into this scene, what you would add? Would those make this scene better?

4. How would you comment on the use of words and that of silence?

5. What elements helps build tension and climax?

6. In your view, what content carries the most weigh in this scene? (ex. honour, manhood, sacrifice, respect, hypocrisy, tyranny, resolution, etc.)

7. In your imagination, how would Hollywood movie depict this scene differently? (ex. Consider gymnastics, clashes of words, dramatic dialogues, ways of telling the story, camera work, expression of emotion, etc.)

If you like, watch the last scene of Blind Fury, a 1989's American remake of Zatoichi Challenged to see a different interpretation of the scene.

Productive follow-up

Some people feel that the best part about the last scene is not words: it is the frugality of them. Do you have a moment in your life which points to the same value where not talking out at the moment seems to be the best thing to practise? For example, one of my friends suffered from the loss of someone he loved. To comfort him I said very little but stay with him in silence to show that I was there for him, understood what he was going through, and share the pain with him by not verbally disturbing too much.

Would you like to write a comment, share a life anecdote, or create a poem about this scene or even part of it?

Here is an example:

Like paper lanterns

flowing down the river

The souls of two warriors

torn apart in the winter

Steel and snow, cold. 


\section{Recommendations for task design}

Task developers might consider providing explicit suggestions for silent processing, verbal responses, or self-talk when necessary. One example provided by Wilkinson and Olliver-Gray (2006) is an instruction that guides students to write down how they feel during exam time and then compare their responses with peers. Stickler, Batstone, Duensing and Heins (2007) suggest that task designers can specify which part of a task does not involve speaking; and can allocate specific moments when students are expected to reflect or silently type their thoughts. Such instructions show the evidence that materials developers can consider including learning strategies to assist students in coping with the learning process.

Sometimes, to avoid disrupting students' productive silent processing, teachers also need to keep silent to ensure that the shared space is observed and respected. It is noted that experienced teachers tend to use silence in their pedagogy more than novice teachers (Vassilopoulos \& Konstantinidis, 2012). Silence may not benefit learning unless teachers can monitor the ways in which learning takes place before, during, and after the productive silent moment. This requires thoughtful task design, clear expectation, and a well-planned management procedure. Such a procedure includes explicit instruction, appropriate wait time, timely support, relevant follow-up strategies, and effective assessment policy. All these strategies should be included in task design with guidance for teachers to use the material.

The challenge of the pedagogy above is that silence, unfortunately, might not be equally favoured by all members in a learning community depending on who shares the learning environment and its broader social norms. It is therefore important for teachers to handle such diverse preferences, with clear expectations when conducting multiple subtasks that allow various learning modes to come into play.

\section{Similar activity design for reflective learners}

Of course, the task introduced in this article is not the only one of its kind. Below are some of my suggestions for working with both highly articulate and less verbal students in the English classroom:

- Asking students yes/no and either/or questions and accept brief responses

- Giving students the opportunity to participate in whole class activities whereby everyone takes note from both conversation and observation

- Using artefacts or props such as video clips, pictures and realia to encourage thinking and questions

- Having small groups of students present new vocabulary to the class by using pictures

- Providing listening activities and reflection time before verbal response

- Creating tasks that involve prediction, such as showing a picture and asking wait happens next, telling a story and pausing for guessing the continuation, and so on. These tasks allow for thoughtful responses and high-quality discussion.

- Supporting learning with graphic organizers, charts and graphs as frames to scaffold writing.

- Creating tasks that require memorisation, such as showing a detailed picture and having students report what they remember.

Classroom tasks sometimes exhibit a stimulating quality that inspires students' thinking. At other times, they might have a routine and humdrum characteristic. When 
learners are inspired, some mind find themselves spending more time in silent thinking; while others may prefer to speak out more with others.

Arguably, learners' silent processing might occur quietly or at times it might develop into the occasional verbal articulation. For example, some reflective students prefer to quietly work on a written task, while other reflective counterparts might switch learning modes and share their thought with peers, especially when the task seems to require some exchange of ideas. Some learners experience such moments of adjusting their participation mode. Empirical research has found that peer influence is a factor which governs how much a learner is willing to participate in classroom discussion (see, for example, Bao, 2014). However, findings from various case studies are often so diverse that they show no consistent formula with regards to what personality leads to talk and silence respectively. You might wish to reflect on your individual inclination in working with peers. To some extent, learners' decision to speak out or to remain quite during a discussion might have to do with peers' behaviour.

\section{CONCLUSION}

Once I was told this anecdote where an eloquent student was telling a classmate: 'I can train you to become more confident at speaking in front of the class'; to which, the other student replied: 'I can train you to become better at listening to others'. As can be inferred from this exchange, since different individuals have their own prioritised ways of learning best, it is hard to assume everyone would benefit from learning in the same manner. In many cases, not talking in class may not denote low confidence but could mean one simply feels confident enough to contemplate a less assertive disposition.

Teachers need to be unbiased about the various ways in which students respond to the demand of a task and should not hold on to any pre-determined expectations, such as assuming that talk is the natural route of learning. In many cases, it is teachers' flexibility, supportive attitudes, and innovative pedagogical strategies that would improve task design by allowing both mental and verbal rehearsal to reach its optimum. Although many communicative tasks might expect learners to switch to an impulsive learning mode, during the actual classroom process, some learners might choose to handle them in a more reflective manner. This is because some might need more self-monitoring time than others before verbal exchange can take place. When this happens, the quality of classroom tasks should not be measured by how much speaking occurs but by the depth of learner engagement.

Silence as mental rehearsal provides conditions for self-directed learning which may be either connected to or independent from the teaching. Pedagogy founded on a profound understanding of productive silence can liberate learners from the constraint of having to produce impulsive, low-quality participation. Silence needs to be managed with acute awareness of why, how, when and how long a student needs it to support their own learning and when the verbal mode of learning should take over. Obligatory talk can be frustrating when learners are required to publicise their half-baked thoughts when they are unprepared to do so. Silence training should be organised to include reflectivity, concentration, outcome and avoidance of idle, unproductive moments-the same way as talk that needs to be directed to enhance learning rather than become mere social time in the classroom. The structure of learning might fundamentally change when this knowledge is applied so that learners can employ both silence and talk as learning tools in conscious, informed ways. 


\section{REFERENCES}

Bao, D. (forthcoming). Silence, talk, and in-betweens: East-Asian students' responses to task challenges at an Australian University. In King, J, \& Harumi, S. (2020). East Asian Perspectives on English Language Education. Bristol, UK: Multilingual Matters.

Bao, D. (2019). The place of silence in second language acquisition. English Language Teaching \& Research 1 (1), August 2019, pp. 26-42.

Bao, D. (2014). Understanding silence and reticence: Ways of participating in second language acquisition. London: Bloomsbury.

Belanoff, P. (2001). 'Silence: reflection, literacy, learning, and teaching', College Composition and Communication, 52(3), 399-428.

Canale, M. and Swain, M. (1980). 'Theoretical bases of communicative approaches to second language teaching and testing', Applied Linguistics, 1(1), 1-47.

Celce-Murcia, M., Dörnyei, Z. and Thurrell, S. (1995). 'A pedagogical framework for communicative competence: A pedagogically motivated model with content specifications', Issues in Applied Linguistics, 6(2), 5-35.

Chambers, J. (2007). 'Silence in SLA research: from personality to identity'. J-Quotes: A Quest for Great Ideas web-site. Retrieved 24 June 2013 at http://jquote.blogspot.com.au/2007/12/silence-in-sla-research-from.html

Colligan, R. C. (1979). 'Predictive validity of the Myklebust Pupil Rating Scales: A twoyear follow up'. Journal of Learning Disabilities, 12, 264-7.

Creelman, A. (2017) Silent learners - a guide. Copenhagen: Denmark: Nordic Council of $\begin{array}{lllll}\text { Ministers, } & \text { accessed } & 6 & \text { November } & 2018 .\end{array}$ http://lnu.divaportal.org/smash/get/diva2:1171709/FULLTEXT01.pdf

Dulay, H., Burt, M. and Krashen, S. (1982). Language two. New York and Oxford: Oxford University Press.

Edwards, A. D. and Westgate, D. P. G. (1987). Investigating classroom talk. London: The Falmer Press.

Ehrich, J. F. (2006). 'Vygotskyan inner speech and the reading process'. Australian Journal of Educational and Developmental Psychology, 6, 12-25.

Feshbach, S., Adelman, H. and Fuller, W. W. (1974). 'Early identification of children with high risk of learning failure'. Journal of Learning Disabilities, 10, 49-54.

Frawley, W. (1997). Vygotsky and cognitive science: Language and the unification of the social and computational mind. Cambridge, MA: Harvard University Press.

Gibbons, J. (1985). 'The silent period: An examination', Language Learning, 35(2), 25567.

Gilmore, P. (1985) Silence and sulking: Emotional displays in the classroom. In D. Tannen and M. Saville-Troike (eds.) Perspectives on silence (pp. 139-162). Norwood, NJ: Ablex.

Gordon, E. M. and Thomas, A. (1967). 'Children's behavioural style and the teacher's appraisal of their intelligence', Journal of School Psychology, 5(4), 292-300.

Granger, C. A. (2004). Silence in second language learning: A psychoanalytic reading. Clevedon, UK: Multilingual Matters.

Gunawardena, C. N., Nolla, A. C., Wilson, P. L., Lopez Islas, J. R., Ramirez-Angel, N. and Megchun- Alpizar, R. M. (2001). 'A cross-cultural study of group processes and development in online conferences', Distance Education: An International Journal,22(1), 85-121.

Harder, P. (1980). 'Discourse as self-expression: On the reduced personality of the secondlanguage learner', Applied Linguistics, 1(3), 262-70.

Karmen, M. (2001). Immemorial silence. New York: State University of New York Press. 
Krashen, S. D. (1985). The input hypothesis: Issues and implications. Harlow: Longman.

Leh, A. S. C. (2001). 'Computer-mediated communication and social presence in a distance learning environment'. International Journal of Educational Telecommunications, $7,109-28$.

Nakane, I. (2012). 9 Silence. The handbook of intercultural discourse and communication, $29,158$.

Oxford, R. (2001). 'Language learning styles and strategies', in M. Celce-Murcia M (ed), Teaching English as a second or foreign language. Boston, MA: Heinle and Heinle, pp. 359-66.

Saville-Troike, M. (1987). 'Bilingual discourse: Communication without a common language'. Linguistics, 25, 81-106.

Saville-Troike, M. (1988). 'Private speech: Evidence for language learning strategies during the 'silent' period', Journal of Child Language, 15(3), 567-90.

Stevenson, H. W., Parker T., Wilkinson, A., Hegion, A., and Fish, E. (1976). 'Predictive value of teacher ratings with young children'. Journal of Educational Psychology, $68,507-17$.

Stickler, U., Batstone, C., Duensing, A., and Heins, B. (2007) Distant classmates: Speech silence in online and telephone language tutorials. European Journal of Open, Distance and E-learning 10 (2), accessed 19 November 2018. http://www.eurodl.org/?p=archives\&year=2007\&halfyear=2\&.. \& article=277

Vassilopoulos, S., and Konstantinidis, G. (2012) Teacher use of silence in elementary education. Journal of Teaching and Learning 8(1), 91-105.

Vygotsky, L.S. (1986). 'Thought and language', in A. Kozulin (ed). Cambridge, Massachusetts: The MIT Press.

Wilkinson, L., and Olliver-Gray, Y. (2006) The significance of silence: Differences in meaning, learning styles, and teaching strategies in cross-cultural settings. Psychologia 49(2), 74-88.

Winegar, L. (1997). 'Can internalization be more than a magical phrase? Notes toward the constructive negotiation of this process', in C. Lightfoot and B. Cox (eds), Sociogenetic Perspectives on Internalization. Mahwah, NJ: Lawrence Erlbaum Associates.

Zembylas, M. (2008). 'The sound of silence in educational pedagogy,' Educational Theory, 54(2), 193-210.

Zembylas, M. and Vrasidas, C. (2007). 'Listening for silence in text-based, online encounters', Distant Education, 28(1), 5-24.

Zembylas, M., and Michaelides, P. (2004) The sound of silence in pedagogy. Educational Theory 54(2), 193-210.

\section{Appendix: Transcript from the video clip}

The following script, which was documented by the author, is for the teacher to use as a way of keeping track what is said in the movie, if you would lie to try out the activity recommended in this article in your classroom. The section 'Using silence as a discussion topic' in the article, including items A, B, C and D, can be printed out as handouts for your students to use. If you have feedback from the implementation, please email it to <dat.bao@monash.edu> for further conversation. 
Dialogue from the last scene of Zatoichi Challenged (1967)

座頭市血煙り街道 Zatōichi chikemurikaidō - 17th episode of 26

Akatsuka: Ichi

Ichi: Master Akatsuka. Is there something I can do for you?

Akatsuka: I want you to hand Shokichi over to me

Ichi: I beg your pardon?

Akatsuka: Just hand him over

Ichi: What's this about, all of a sudden?

(turning to Shokichi) Shokichi, do you have some history with this samurai?

Shokichi: (silent) No, I've never seen him before

Ichi: What's your business with Shokichi, Master Akatsuka?

Akatsuka: (silent)

Ichi: If you don't tell me that, how do you expect me to comply?

Akatsuka: I'm going to kill him.

Ichi: (silent) Have you gone mad?

Akatsuka: I'm on official government business. When I cut down Torikoshi, that, too, was official business. I would have killed Gonzo as well, but you saved me the trouble. Perhaps now you can understand my position.

Ichi: I can understand why you go after Gonzo and the corrupt officals, but this man's only crime was being forced by Gonzo to -

Akatsuka: Forced or not, he's guilty of creating designs for the forbidden items. It was his misfortune to have been born with such a gift.

Ichi: I still do't understand why drawing a few pictures should -

Akatsuka: My orders are to destroy all traces of the plot, whether man or object, to prevent it from becoming a scandal.

Ichi: Master Akatsuka, though they only met today, Shokochi is that boy's father. This is their first chance to live happy as a family. Please just look the other way and let them go. Please have mercy on them.

Akatsuka: The law has no mercy. If you refuse to turn him over, I will have to kill you as well.

Omitsu: (down on her knees bowing) Please let Shokichi go. For the sake of the child, I beg you.

Akatsuka: Stand in my way and I won't hesitate to kill even a woman or child.

Shikochi: Wait! Master Ichi, I'll accept this as my fate. Please look after Ryota and Omitsu. Ichi: (throwing Shikochi to the ground) Shikochi stay with me.

Akatsuka: Ichi! 
Ichi: You samurai are so full of yourselves. So long as you have orders, you don't care what you do to people.

Akatsuka: (angrily) Step aside.

Ichi: (pause) You have to take shokichi (pause) over my dead body. So long as you've got orders, you don't care what you do to people.

Akatsuka: (more angrily) Step aside.

Ichi: (long pause) (slowly with emphasis) You have to take Shokichi over my deadbody. Akatsuka: (with emphasis) I'm warning you.

Ichi: (to the family) Don't let Ryota see this.

(Fighting scene)

A servant (running in from a distance): Master Akatsuka!

Akatsuka: That's Shikochi! Kill him!

(Ichi killed the man)

(Ichi and Akatsuka wrestled, then stopped in long silence)

Akatsuka: Ichi (long pause), you win.

(Long silence - Akatsuka put his sword back into his sheath/scabbard and walked away. Tension eases; mood changes)

\section{End of scene}

